\title{
EFEK STRATEGI DIVERSIFIKASI PRODUK DAN JASA TERHADAP PERTAMBAHAN PENUMPANG PADA JALUR UTAMA TRANSPORTASI
}

\author{
Prayitno $^{1}$, Hesti widianti ${ }^{2}$ \\ Email: Pra.yitno.py17@gmail.com ${ }^{1}$, Email: Hesti28widianti@gmail.com² \\ ${ }^{1}$ Politeknik Trisila Dharma Tegal \\ ${ }^{2}$ Politeknik Harapan Bersama Tegal
}

\begin{abstract}
Descriptive research is used to gain insight into the size of product diversification, service quality and the perceived availability of consumers offered by transportation equipment entrepreneurs in relation to the service quality model perceived by Gronroos (1994) to develop as a functional and technical quality dimension. Bus Entrepreneurs can provide the desired means of transportation by passengers supported by toll lines that operate along the main line to be a great opportunity for Bus entrepreneurs, product diversification means that reducing seat seats to be the ultimate choice that should be done by Bus entrepreneurs so that the clarity of departure can obtained by passengers and good service becomes a supporting factor in addition to the existence / ease of getting Bus transportation.
\end{abstract}

\section{Pendahuluan}

Alat Transportasi menjadi andalan utama masyarakat mencapai tujuan mobilitas berpindah dari satu tempat ke tempat lain secara cepat, tanpa alat transportasi yang baik mobilitas masyarakat zaman modern akan tertinggal untuk menyelesaikan pekerjaan yang sifatnya fisik seperti pergi ke kantor, menghadiri rapat, acara acara seremonial yang harus dihadiri tepat waktu. Alat transportasi terbagi atas transportasi on line dan transportasi konvensional. Zaman teknologi transportasi on line tidak menemui kendala yang berarti sebab sifatnya masuk dalam transportasi jarak pendek, menurut data comScore per Desember 2017, tercatat sebanyak 15,73 juta orang menggunakan aplikasi transportasi online di ponsel Android. Di antaranya Go-Jek, Grab, dan Uber, yakni 29,6 persen dari seluruh pengguna aplikasi mobile.

Namun, bagaimana jika masyarakat akan mobilitas jarak jauh antar provinsi tentu hal itu akan menggunakan alat transportasi konvensional yang praktis, cepat dan tepat sampai ke tujuan. Pilihan alat transportasi saat ini adalah Kreta Api, Bus dan Travel. Kreta api masih menjadi pilihan utama masyarakat karena lebih tepat waktu sampai tujuan dan nyaman namun ada sisi kelemahanya bahwa Kreta api masih menggunakan jam tertentu dalam keberangkatan jadi tidak dapat setiap waktu ada. Pilihan kedua masyarakat ada pada Bus sebab alat transportasi ini lebih mudah di jumpai di jalan - jalan untuk bus Humel, di Terminal dan agen untuk Bus Patas namun alat transportasi Bus juga memiliki kelemahan yaitu jumlahnya yang melebihi jumlah penumpang yang ada sehingga tidak selalu terisi penuh kursi yang tersedia pada akhirnya tidak jadi berangkat ketempat tujuan sehingga penumpang kecewa, tarif yang lebih mahal dari Kreta api, kurangnya pelayanan dan pilihan masyarakat yang terakhir adalah Travel sebab mampu menjangkau daerah pelosok, sampai tujuan dan praktis namun kelemahanya adalah travel tidak tepat waktu sampai ke tujuan, tertalu sempit kendaraanya dan tidak nyaman dalam pelayanan.

Penelitian ini fokus pada alat Transportasi jarak jauh Bus antar kota antar propinsi di jalur utama ( jalur jalan Nasional ) dengan titik pusat Jakarta. Bus pada tahun 90 an menjadi alat transportasi pilihan utama masyarakat yang mobilitas jarak jauh, tercatat pada setiap keberangkatan jumlah penumpang melebihi kapasitas tempat duduk yang tersedia, penumpang 70 sedangkan kapasitas kursi tersedia 59 penumpang untuk seat 3.2 ( data PO ) Namun, keberadaanya tergusur oleh Kreta api pada awal tahun 2000an dengan beroperasinya 
dua jalur dan di hilangkanya pedagang asongan, ketepatan waktu berangkat dan ketepatan tujuan diperparah dengan bertambahnya masyarakat ekonomi menengah yang membeli mobil MPV untuk dijadikan Travel. Kondisi tersebut memerlukan inovasi baru dalam produk, pelayana jasa Bus agar dapat bangkit dan bersaing dengan Kreta api dan Travel.

Keinginan umum dari penumpang alat transportasi adalah ketepatan keberangkatan, ketepatan sampai tujuan, pelayanan yang baik serta mudah mendapatkannya. Dari keinginan umum penumpang pemilik Bus mampu membuat trobosan, ketepatan berangkat yang menjadi permasalahan Bus adalah jumlah penumpang kurang dari jumlah kursi yang disediakan sehingga tidak jadi berangkat, ketepatan sampai tujuan yang menjadi permasalahan adalah makin berkembangnya alat transportasi jalur menjadi sibuk dan macet akhirnya tidak sampai tujuan tepat waktu, pelayanan yang baik memang diakui kurang sebab penumpang yang sedikit menjadikan semangat kerja menurun untuk pelayanan dan hanya satu yang masih menjadi andalan yaitu mudah dijumpai keberadaan Bus di Terminal dan agen namun karena sepi penumpang tidak pernah berangkat. Dari data tersebut dapat dibuat kesimpulan sementara bahwa pelayanan bisa ditingkatkan apabila jumlah penumpang meningkat, ketepatan keberangkatan bisa dilakukan apabila jumlah penumpang cukup dengan kursi yang disediakan, ketepatan sampai tujuan akan bisa bila jalur tidak macet. Penyelesaian yang diakukan pemilik Bus adalah dengan diversifikasi produk dan jasa.

Strategi diversifikasi produk memiliki pengaruh penting terhadap kinerja perusahaan (Geringer, Beamish, \& da Costa, 1989; Hitt et al., 1997; Kim et al., 1989). Lalu bagaimana untuk mendivesifikasikan produk alat Transportasi Bus ?, Hitt dkk. (1997) menemukan bahwa diversifikasi produk secara positif meningkatkan kinerja perusahaan yang terdiversifikasi. Sebaliknya, Geringer, Tallman, dan Olsen $(2000)^{[1]}$ dan Tallman dan Li (1996) tidak menemukan bukti signifikan untuk efek interaktif antara internasional dan diversifikasi produk. Selanjutnya, Kim et al. $(1989)^{[2]}$ menemukan bahwa efek diversifikasi produk bergantung pada sejauh mana diversifikasi. Mereka menemukan bahwa diversifikasi produk hanya berlaku untuk perusahaan dengan tingkat diversifikasi rendah, tetapi tidak berpengaruh pada kinerja mereka dengan tingkat diversifikasi yang tinggi(Park \& Shawn, 2013). Capar dan Kotabe (2003) ${ }^{[3]}$ mengemukakan bahwa hubungan antara diversifikasi dan kinerja industri yang spesifik. Mereka berpendapat bahwa model untuk perusahaan manufaktur sesuai untuk perusahaan jasa(Park \& Shawn, 2013). Pendapat ini diperkuat lagi, efek moderasi dari diversifikasi produk terkait dengan biaya dan manfaat yang bervariasi tergantung pada konten diversifikasi produk (Park \& Shawn, 2013).

\section{Metodologi}

Penelitian deskriptif digunakan untuk mendapatkan wawasan tentang ukuran diversifikasi produk, kualitas layanan dan ketersediaan yang dirasakan konsumen yang ditawarkan oleh pengusaha alat Transportasi sehubungan dengan model kualitas layanan yang dirasakan dikembangkan oleh Gronroos (1994) adalah dimensi kualitas fungsional dan teknis. Dimensi kualitas teknis adalah APA yang didapatkan pelanggan (hasil) sementara variabel yang terkait dengan layanan fungsional mengacu pada BAGAIMANA pelanggan mendapatkan (Proses). Data primer dikumpulkan untuk penelitian. Ukuran sampel yang digunakan adalah 100 responden. Tiga Perusahaan Bus terbesar yang berada di wilayah pantura berdasarkan banyaknya jumlah Bus yang dimiliki dan yang mulai berubah dalam tata kelola mengikuti perkembangan kemajuan dunia transportasi dan perubahan minat penumpang. Para responden dipilih atas dasar kemudahan sampling. Kuesioner diberikan secara pribadi kepada pelanggan yang terhormat baik dalam bahasa Indonesia dan juga dalam bahasa daerah masing-masing untuk pemahaman yang lebih baik. 


\section{Pembahasan dan Hasil}

Didalam Undang-undang No 22 tahun 2009 tentang Lalu Lintas dan Angkutan Jalan kendaraan bermotor didefinisikan sebagai setiap Kendaraan yang digerakkan oleh peralatan mekanik berupa mesin selain Kendaraan yang berjalan di atas rel.

Yang dimaksud dengan "mobil bus" adalah Kendaraan Bermotor angkutan orang yang memiliki tempat duduk lebih dari 8 (delapan) orang, termasuk untuk Pengemudi atau yang beratnya lebih dari 3.500 (tiga ribu lima ratus) kilogram. Istilah bus ini berasal dari bahasa Latin, omnibus, yang berarti "(kendaraan yang berhenti) di semua (perhentian)". Ukurannya bermacam-macam. Bus besar untuk beroperasi di jalan-jalan raya yang lebar dan transportasi jarak jauh. Bus kecil beroperasi di kampung atau jalan kecil antar kota kabupaten. Bentuknya ada dua macam yaitu bentuk berhidung dan tanpa hidung. Sekarang kebanyakan bus didesain tanpa hidung sehingga lebih praktis dan ringkas.

Bus atau dalam bahasa Inggris disebut Coach atau motorcoach biasanya adalah kendaraan yang dirancang untuk bepergian jarak jauh dari bus biasa. Sebagai hasilnya dia dilengkapi dengan kursi yang lebih nyaman, sebuah ruangan untuk tempat bagasi, dan mesin yang lebih besar. Kendaraan ini biasanya lebih tinggi dari bus biasa, dan dilengkapi dengan A.C., toilet, dan sistem audio/video.
BUS AC 59 SEATS (2-3) + 1 KURSI CD

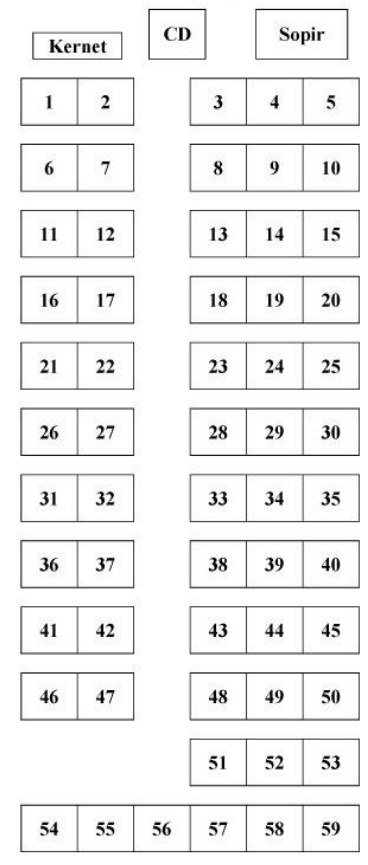

BUS NON AC 54 SEATS (2-3)

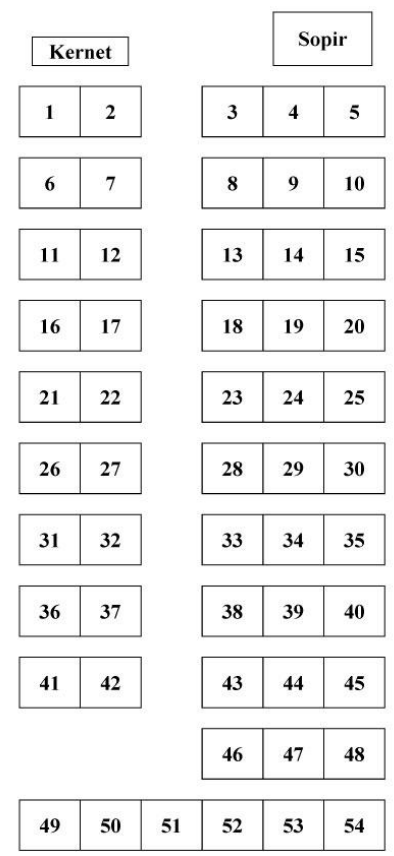

Gambar 1. Denah tempat duduk Bus Normal

Secara umum tempat duduk Bus terdiri dari 50 seat sampai 59 seat ( gambar 1 ), dengan kondisi sekarang hal itu sulit untuk dioperasikan karena keberangkatanya menunggu penumpang penuh padahal penumpang dikejar oleh waktu di temapat tujuan namun bus tidak segera berangkat, apabila tidak memenuhi seat maka bus tidak jadi berangkat dalam hal ini penumpang dirugikan oleh pihak Bus, maka dari survei yang dilakukan 73 responden dari 100 responden menyesal naik Bus karena tidak ada kejelasan dalam pemberangkatan.

Divesifikasi produk dapat dilakukan untuk untuk memastikan keberangkatan penumpang ke temapat tujuan, diversifikasi dalam hal ini adalah dengan cara mengurangi tempat duduk menjadi 24 seat agar penumpang merasa nyaman dan kepastian keberangkatan. 


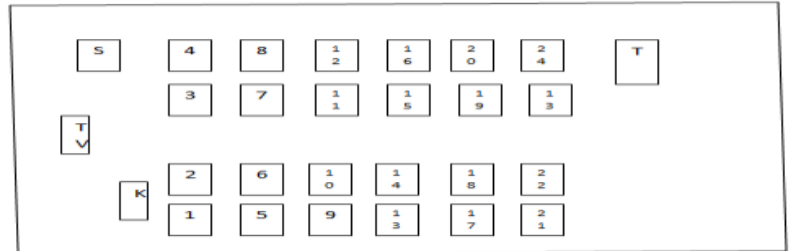

Keterangan

$\mathrm{S}=$ sopir,$\quad \mathrm{K}=$ kemet,$\quad \mathrm{TV}=$ televisi,$\quad \mathrm{T}=$ Toilet

1-24 Seat Penumpang

Gambar 2. Seat Penumpang setelah perubahan

Dengan mengurangi tempat duduk ( gambar .2 ) dari yang semula 59 menjadi seat 24 alat transportasi Bus memastikan keberangkatan tepat waktu. Secara logika ini sudah menyamakan dengan alat transportasi lain seperti Kreta Api dan Travel bahwa kepastian keberangkatan sehingga calon penumpang tidak ragu bila ingin memilih alat transportasi Bus.

Kwalitas pelayanan yang dipersipakan oleh crew Bus terdiri dari, agen, kontrol, sopir dan kernet.adapun agen mempersiapkan tiketing, administrasi untuk makan di tengah perjalanan, kontrol memastikan bahwa penumpang sesui dengan tempat duduk dan memastikan tidak ada penumpang yang naik di tengah jalan tanpa sepengetahuan dari agen maupun kantor pusat, kernet menjaga kebersihan Bus, melayani kebutuhan ppenumpang, mengawal perjalanan dari sisi perjalanan dan sopir mengemudikan Bus dengan nyaman sehingga penumpang merasa aman sampai ke tujuan. Hasil survei menunjukan bahwa 87 penumpang menginginkan pelayanan yang baik dari crew Bus, 9 penumpang tidak mempermasalahkan pelayanan dan 4 penumpang tidak menjawab.

Dari sudut pandang pelanggan, Roland Berger Consultants (2003, p. 8) mendefinisikan masalah yang diberikan sebagai "Produk yang tidak ditemukan, tidak ditemukan di lokasi yang diharapkan. ". Dengan ini, mereka membedakan antara klasik, penempatan ganda dan delisting outof-stocks.Campo et al. (2004) dan Sloot (2006) melihat kehabisan stok dari aspek temporal, bisa sementara atau permanen. Keberadaan produk/ Bus ada kapanpun pada saat yang dibutuhkan sangant menentukan penumpang memilih alat transportasi Bus, Bus memiliki kelebihan setiap jam ada yang bereangkat ke temapat tujuan, keberadaannya mudah ditemui di tempat - tempat umum, terminal, agen perjalanan mejadi keunggulan dibandingan dengan kereta api dan travel. Dengan didukung fasilitas yang baru yaitu beroperasinya jalur toll di sepanjang jalur transportasi utama sehingga waktu tempuh Bus sama dengan waktu tempuh Kereta api untuk sampai ke tempat tujuan. Hasil survei penumpang Kereta api mengapa mereta memilih alat transportasi kereta api adalah alasan pertama tepat waktu sampai ke tujuan dan keberangkatan sebesar 78 responden, kenyamanan 22 responden. Namun, 90 responden menjawab tidak menyukai dengan waktu tertentu saja jadwal keberangkatan kereta api, 10 responden tidak mempermasalahkan itu. Tentunya hasil survei penumpang kereta api menguntungkan alat transportasi Bus untuk masa depan sebab ; dengan berlakunya jalur toll sepanjang jalur utama menjadikan waktu tempuh Bus sama dengan waktu tempuh kereta api untuk sampai tujuan, Bus mampu berangkat setiap jam namun jadwal kereta api beberapa kali setiap hari, pelayanan yang nyaman serta keberadaan Bus yang mudah dijumpai dimanapun menjadi daya tarik tersendiri.

\section{Kesimpulan}

Penumpang menginginkan kenyamanan dalam mobilitas berpindah dari satu temapat ke temapat lain, kepastian keberangkatan dan ketepatan sampai tujuan menjadi alasan utama penumpang memilih alat transportasi serta pelayayanan yang baik dan kemudahan mendapatkan alat transportasi tersebut. Pengusaha Bus dapat menyediakan alat transportasi yang diinginkan oleh penumpang dengan didukung oleh jalur toll yang beroperasi di sepanjang jalur utama menjadi kesempatan yang besar bagi pengusaha Bus, diversifikasi produk yang berarti mengurangi seat tempat duduk menjadi pilihan utam yang harus dilakukan oleh pengusaha Bus sehingga kejelasan pemberangkatan dapat diperoleh oleh penumpang lalu pelayanan yang baik menjadi faktor pendukung disamping 
keberadaan / kemudahan mendapatkan alat transportasi Bus. Apabila sudah terpenuhi semua maka kemungkinan besar penumpang Bus akan kembali ke era tahun 90an dimana akan menjadi alat transportasi favorit sebab ketepatan pemberangkatan, ketepatan sampai tujuan, pelayanan yang bagus serta kemudahan mendapatkan Bus yang diinginkan tanpa harus menunggu jadwal yang sudah ditentukan.

\section{Daftar Pustaka}

[1] Alma. (2004). Jurnal FMAS Ekonomi, Manajemen dan Bisnis. Vol.1 No.1 Ok tober 2007, 263Aldlaigan, A., and Buttle, A. (2002). SYSTRA-SQ: a new measure of banks service quality.International Journal of Service Industry Management, Vol. 13 No. 4, pp. 362-81.

[2] Aiken, L. S., \& West, S. G. (1991). Multiple regression: Testing and interpreting interactions.Newbury Park, CA: Sage.

[3] Baysinger, B., \& Hoskisson, R. (1989). Diversification strategy and $R \& D$ intensity inmultiproduct firms. Academy of Management Journal, 32(2): 310-332.

[4] Benston, G. J. (1985). The validity of profits-structure studies with particular reference to theFTC's line of business data. American Economic Review, 75: 37-67.

[5] Bergh, D. D. (1993). Don't "waste" your time! The effects of time series errors inmanagement research: The case of ownership concentration and research anddevelopment spending Journal of Management, 19(4): 897899.

[6] Bethel, J., \& Liebeskind, J. P. (1998). Diversification and the legal organization of the firm.Organization Science, 9: 49-67.

[7] Bowman, E. H., \& Helfat, C. E. (2001). Does corporate strategy matter? StrategicManagement Journal, 22(1): 1-24.

[8] Buhner, R. (1987). Assessing international diversification of West German corporations.Strategic Management Journal, 8: 25-37.
[9] Capar, N., \& Kotabe, M. (2003). The relationship between interna-tional diversification andperformance in service firms. Journal of International Business Studies, 34: 345-355.

[10] Chandler, A. (1962). Strategy and structure: Chapters in the history of American industrialenterprise. Cambridge: MIT Press.

[11] Chang, S. L., \& Singh, H. (2000). An evolutionary perspective on diversification andcorporate restructuring: Entry, exit and economic performance during 19811989.Strategic Management Journal, 17(8): 587-611.

[12] Christensen, H. K., \& Montgomery, C. A. (1981). Corporate economic performance:Diversification strategy versus market structure. Strategic Management Journal, 2(4):327-343.

[13] Cohen, W. M., \& Levinthal, D. A. (1990). Absorptive capacity: A new perspective onlearning and innovation. Administrative Science Quarterly, 35: 128-152.

[14] Contractor, F. J., Kundu, S. K., \& Hsu, C. C. (2003). A three-stage theory of internationalexpansion: The link between multination-ality and performance in the service sector.Journal of Interna-tional Business Studies, 34: 5-18.

[15] Delios, A., \& Beamish, P. W. (1999). Geographic scope, product diversification, and thecorporate performance of Japanese firms. Strategic Management Journal, 20: 711727. 